
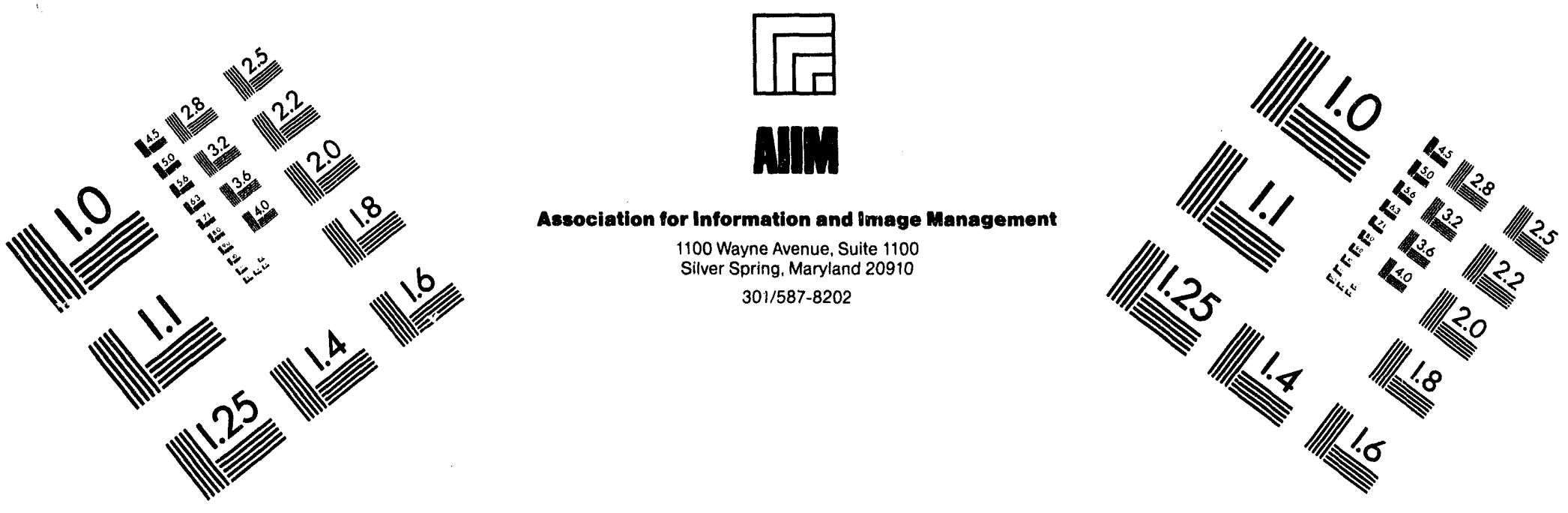

\title{
Centimeter
}

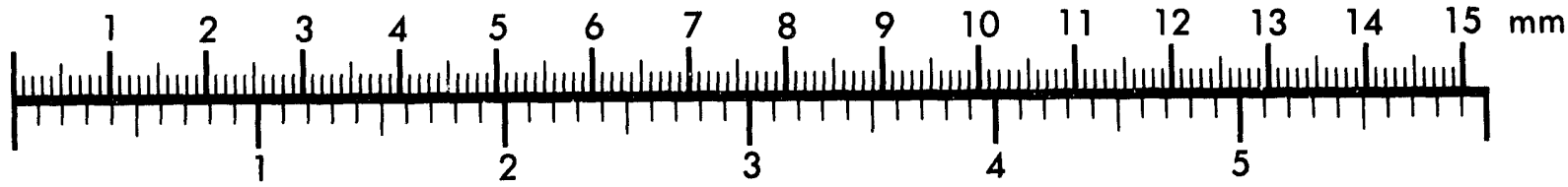
Inches
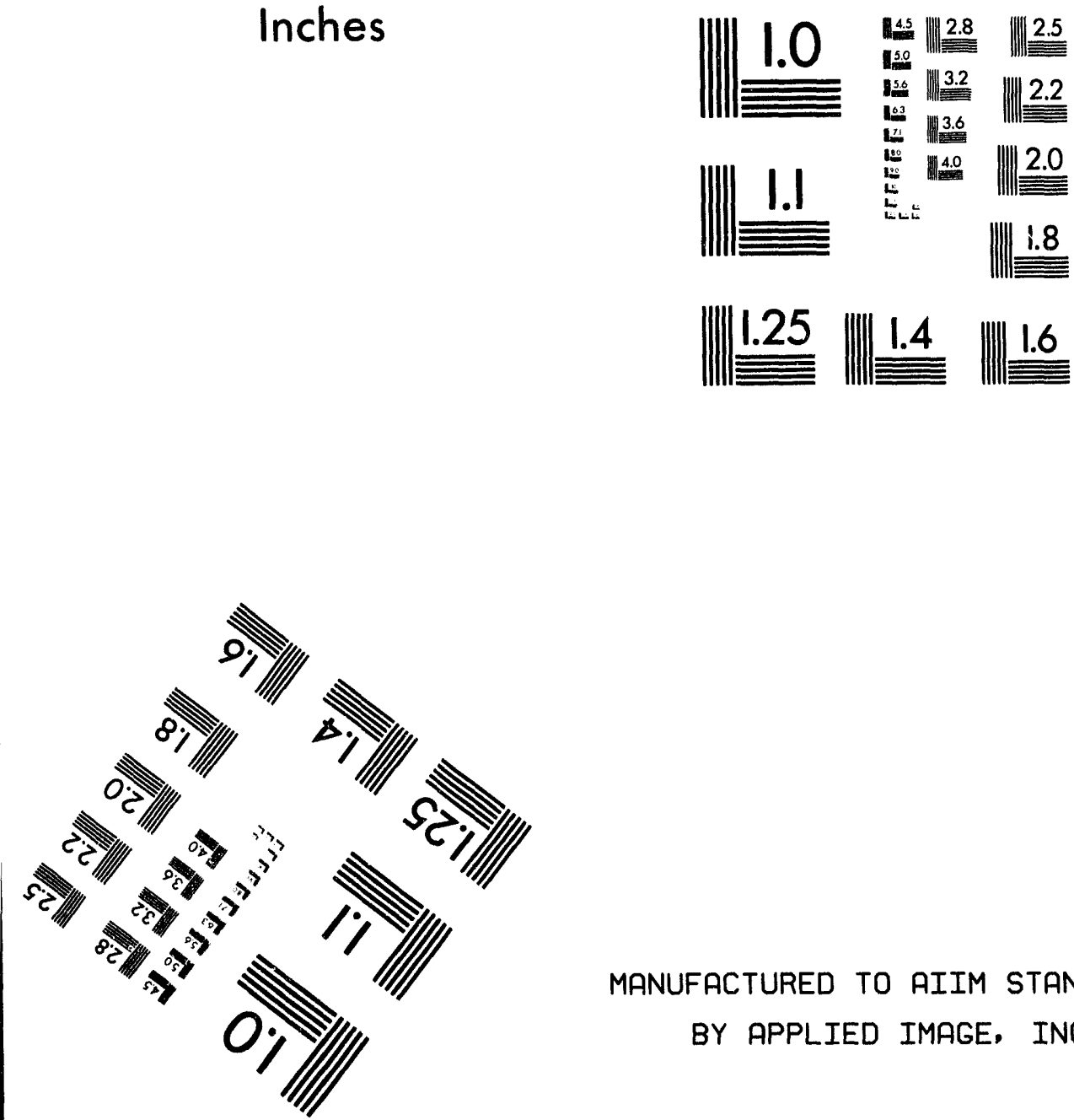

MANUFACTURED TO AIIM STANDARDS

BY APPLIED IMAGE, INC.

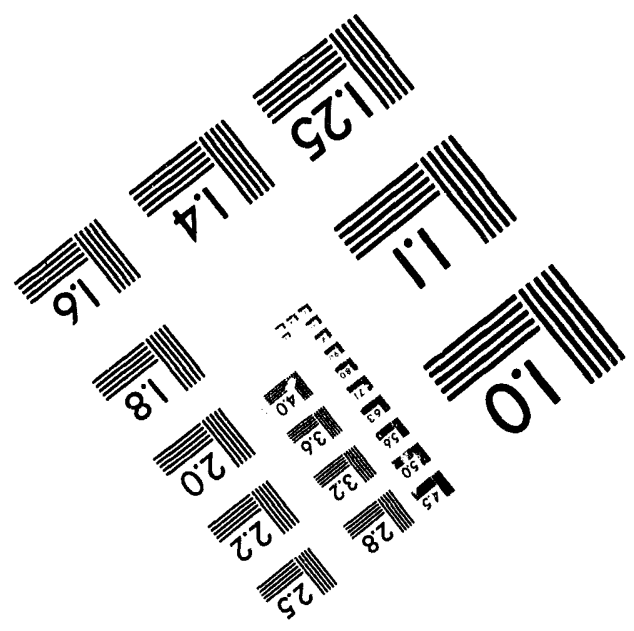



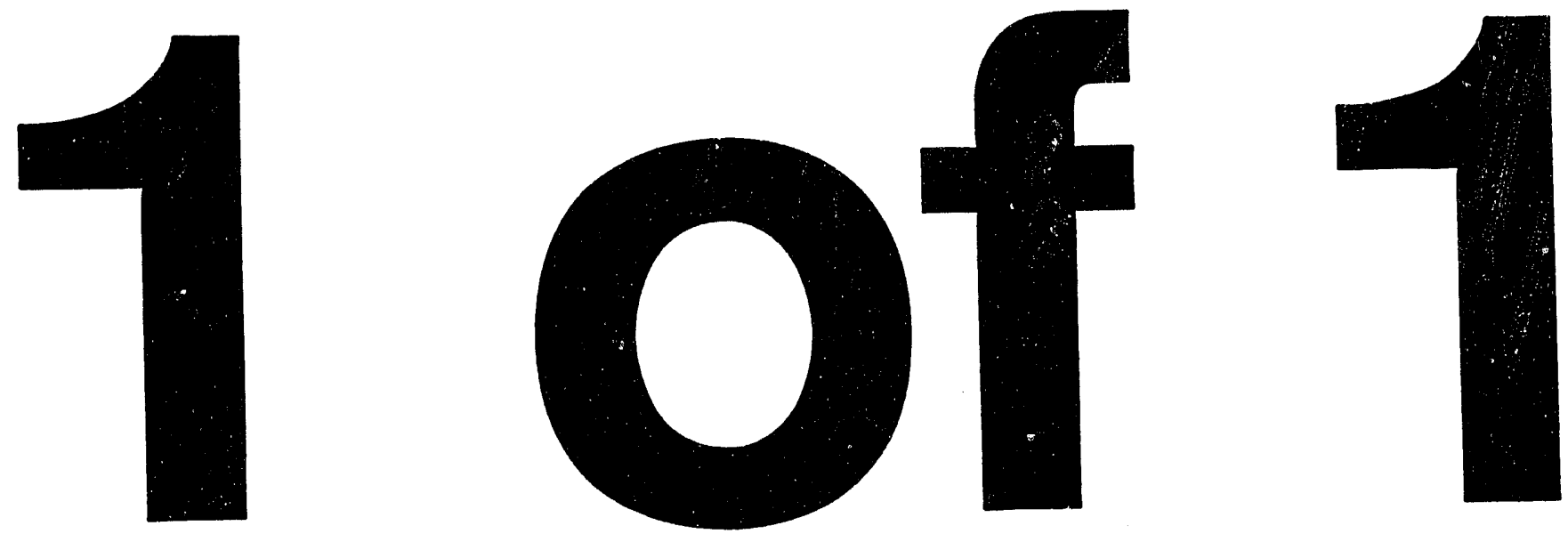


\title{
ANL/CHM/PP-. 19404
}

\section{On the Formation of Iron(III) Oxides Via Oxidation of Iron(II)*}

\author{
Roberta Bongiovannia, Enrico Borgarellob \\ Dan Meiselc and Exio Pelizzettia
}

(a) Università di Torino Dipartimento di Chimica Analitica

(b) Eniricerche S.p.A., Milanol

(c) Argonne National Laboratory, Argonne, USA IL
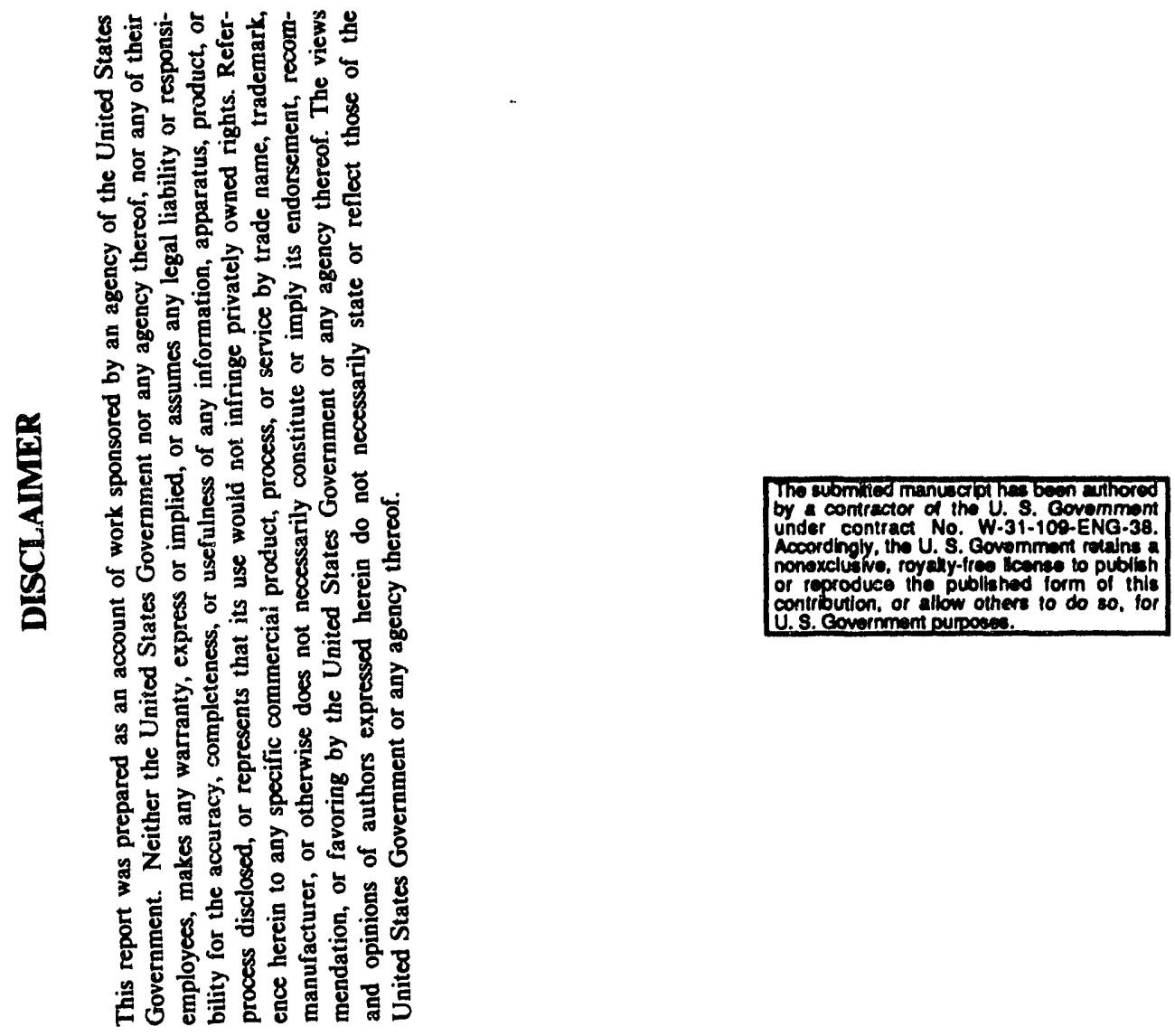

*Work at Argonne performed under the auspices of the Office of Basic Energy Sciences, Division of Chemical Science, US-DOE under contract number W-31-109-ENG-38. 
ON THE FORMATION OF IRON(III) OXIDES VIA OXIDATION OF IRON(II)

\author{
Roberta Bongiovanni ${ }^{\mathbf{a}}$, Enrico Borgarello ${ }^{\mathbf{b}}$, \\ Dan Meisel ${ }^{c}$ and Ezio Pelizzetti ${ }^{a}$
}

\begin{abstract}
(a) Università di Torino Dipartimento di Chimica Analitica
(b) Eniricerche S.p.A, Milano

(c) Argonne National Laboratory, Argonne, USA IL
\end{abstract}

\title{
DISCLAIMER
}

\begin{abstract}
This report was prepared as an account of work sponsored by an agency of the United States Government. Neither the United States Government nor any agency thereof, nor any of their employees, makes any warranty, ex ress or implied, or assumes any legal liability or responsibility for the accuracy, completeness, or usefulness of any information, apparatus, product, or process disclosed, or represents that its use would not infringe privately owned rights. Reference herein to any specific commercial product, process, or service by trade name, trademark, manufacturer, or otherwise does not necessarily constitute or imply its endorsement, recommendation, or favoring by the United States Government or any agency thereof. The views and opinions of authors expressed herein do not necessarily state or reflect those of the United States Government or any agency thereof.
\end{abstract}




\begin{abstract}
The formation of iron oxides in aqueous salt solutions is reviewed. The discussion is focussed on the oxidation of iron(II) and the following hydrolysis process that leads to the formation of a solid phase from homogeneous solutions. Results from our own studies on the kinetics of the oxidation reactions and the ensuing growth processes are presented.

The use of UV-Vis spectroscopy as a tool in the study of the hydrolytic process is critically analysed.
\end{abstract}

\title{
INTRODUCTION
}

Iron oxides appear in nature in many minerals; they are used as catalysts, catalyst carriers, pigments and magnetic media. The end products of the corrosion of iron and steel invariably consist of iron oxides. An important biological function such as iron storage in the human body is performed through oxides formation in ferritin. This short list is sufficient to demonstrate that understanding iron chemistry has fundamental significance and importance in geological, environmental, metallurgical, industrial and biological context.

Iron oxides are synthesized in the laboratory mainly by forced hydrolysis of iron(III) solutions. An alternative route is the oxidation of iron(II).

In this report we present a survey of the recent literature on this last topic. Some results from our recent studies are included as well, aiming to clarify the first steps of the reaction, long before the appearance of a bulk solid phase. The techniques employed for this purpose are the stopped flow and the pulse radiolysis. These results have to be considered preliminary and will only briefly be discussed.

Because the oxidation of iron(II) can be easily followed by monitoring the absorbance of the species at the higher oxidation state, UV-Vis spectrophotometry was utilized in all our experiments. Many examples of employing this technique can be found in the literature. Therefore, a brief 
account of iron(II) and iron(III) UV-Visible spectroscopy is given in the next paragraph.

\section{IRON II/III UV-VISIBLE SPECTROSCOPY:BASIC CONCEPTS}

An enormous amount of work has been done on the subject since the 1930 's, when the first photometers became availa-ble[1].

The spectrum of the reduced species, $\mathrm{Fe}^{2+}$, shows no features, as in slightly acidic solutions it exists mainly as $\mathrm{Fe}^{2+}$ ions [2]. The oxidised ion, $\mathrm{Fe}^{3+}$, on the other hand, has absorption characteristics which depend strongly on the solution composition. In fact iron(III) is much more hydrolysable than iron(II) as shown in table I [3], therefore can produce many different species, depending on the experimental conditions.

The hydrolysis of iron(III) strongly depends on counter-ions, $\mathrm{pH}$ and time of aging. Counter-ions like nitrate and perchlorate [4] show the least tendency for complex formation with iron(III), while sulphate and chloride [5-6] form various coloured complexes.

When examining iron perchlorate and nitrate solutions, on which most of the hydrolysis studies have been conducted, we found that at very low $\mathrm{pH}(<2)$, the UV-Vis spectrum of iron(III) shows the typical bands ( $240 \mathrm{~nm}$ ) of the species $\mathrm{Fe}^{3+}$. Peaks are found at the following wavelength:

$\lambda=247 \mathrm{~nm}$ for iron(III) nitrate in $\mathrm{HNO}_{3} 1 \mathrm{M}$

$\lambda=239 \mathrm{~nm}$ for iron(III) perchlorate in $\mathrm{HClO}_{4} 1 \mathrm{M}$

These data agrees well with published reports $[7,8]$.

Changing the $\mathrm{pH}$ modifies the spectrum of iron(III) because of the generation of hydrolysis products. In particular iron nitrate even at $\mathrm{pH} 2$ shows two maxima, at $240 \mathrm{~nm}$ and $300 \mathrm{~nm}$ respectively; iron perchlorate at the same $\mathrm{pH}$ exhibits maxima at 205 and $300 \mathrm{~nm}$. The new peak at $300 \mathrm{~nm}$ is commonly assigned to the species $\mathrm{Fe}(\mathrm{OH})^{2+}$.

The spectra of the solutions at different $\mathrm{pH}$ show two isosbestic points at $\lambda=272$ and $225 \mathrm{~nm}[9]$. 
We noticed that the aging of the solution enhances the hydrolysed species, $\mathrm{Fe}(\mathrm{OH})^{2+}$ at $300 \mathrm{~nm}$.

\section{THE HYDROLYSIS REACTIONS AND PRODUCTION OF IRON OXIDES.}

There are two ways to produce iron(III) oxides; either by direct hydrolysis of iron(III) or by oxidation of iron(II) and subsequent hydrolysis.

The main steps of the hydrolytic process are initially the formation of low molecular weight species as those listed in table I. This is followed by the formation of high molecular weight products ( a red cationic polymer) and their conversion to oxide phases upon aging. Alternatively, precipitation of the oxides from the low molecular weight precursors may occur.

Starting from $\mathrm{Fe}^{3+}$ ions, hydrolysis can be induced by diluting the solution with water (limiting the hydrolysis to the formation of low molecular weight species), by addition of base [9] or by increasing the temperature [1012].

The first low molecular weight products are mainly $\mathrm{Fe}(\mathrm{O} / \mathrm{I})^{2+}$, $\mathrm{Fe}_{2}(\mathrm{OH})_{4}{ }^{2+}$ and $\mathrm{Fe}(\mathrm{OH})_{2}{ }^{+}[13,2,3]$. Magnetic, kinetic and infrared data verified the presence of dimeric species such as $\mathrm{Fe}_{2}(\mathrm{OH}){ }_{4}{ }^{2+}$. Similar products are directly obtained through the oxidation of iron(II); in fact the equilibria involving these low molecular weight species are established as soon as the oxidation takes place. The reactions of dimeric species are much slower than those involving only monomers [2].

Several examples of the UV-Visible spectra of various relevant mixtures are given in figure 1. All were recorded at the same time after mixing of either $\mathrm{Fe}\left(\mathrm{ClO}_{4}\right)_{3}$ with $\mathrm{NaOH}$ or $\mathrm{FeSO}_{4}$ with $\mathrm{H}_{2} \mathrm{O}_{2}$. We noticed that inspite the different reagents the spectra were essentially identical.

In order to form species of higher molecular weight multiple reaction pathways need to occur simultaneously, as depicted in table II. The process is known as olation, because it occurs through the formation of hydroxide bridges of the kind $-\mathrm{Fe}-\mathrm{OH}-\mathrm{Fe}{ }_{\sim}[14]$. 
A second type of polymerisation, also involved in the formation of oxides, is oxolation; in this case oxobridges are formed through one of the following reactions:

$$
-\mathrm{Fe}-\mathrm{OH}+\mathrm{HO}-\mathrm{Fe} \sim \rightarrow-\mathrm{Fe}-\mathrm{O}-\mathrm{Fe} \sim+\mathrm{H}_{2} \mathrm{O}
$$

Alternatively, the oxo-bridged polymers may be obtained by deprotonation of hydroxide bridges:

$$
-\mathrm{Fe}-\mathrm{OH}-\mathrm{Fe}-\quad \rightarrow \quad-\mathrm{Fe}-\mathrm{O}-\mathrm{Fe}-+\mathrm{H}^{+}
$$

Hence, via olation and oxolation, the evolution from $\mathrm{Fe}^{3+}$ to iron oxides may be visualised as a polymerisation upon deprotonation, because there is a progressive elimination of $\mathrm{H}^{+}$followed by formation of polymeric species with olo and oxo linkages.

A comprehensive discussion of the mechanism of these reactions and the experimental evidence that verified it, was given by Flynn [9]. The hydrolytic polymer was isolated by Spiro et al. [15,16] and Quirk et al. [17] as an amorphous solid by gel filtration and lyophilisation; chemical analysis of the $\mathrm{OH} / \mathrm{Fe}$ ratios indicated that the polymer is cationic.

Upon aging of the polymer, precipitation of the oxides ensues. It is observable after few days and can continue for months. The process is explained by various authors in different ways: Spiro $[15,18]$ inferred a two step process, consisting of hardening of the polymer and of agglomeration; De Bruyn $[19,20]$ distinguished the formation of polymer spheres from low molecular weight species, aggregation of the spheres and subsequent precipitation. Flynn in his review [9] combines the two schemes as shown in table III, where an overview of the current understanding is presented.

Precipitation of solids from low molecular weight species is also discussed by other authors in the literature $[21,22]$.

In some of our own experiments we did not notice any red polymeric products. The solutions following either direct hydrolysis of iron(III) or hydrolysis via oxidation of iron(II), stayed transparent for a while before the 
appearance of a coloured precipitate. Spectra of these transparent solutions showed a continuous red-shift and broadening of a strong and unique absorption peak at $205 \mathrm{~nm}$ upon aging of the solutions (Figure 2). The redshift was more pronounced when the solutions were heated, indicating the presence of small colloidal particles in the suspension [23-25].

The particles are not visible initially, but upon aging, generally within a few hours, they become visible eventually forming yellowish-brownish flocs. The spectra in figure 2 closely resemble those reported by Faust and Hoffmann [26] on examining colloidal suspensions of $\mathrm{Fe}_{2} \mathrm{O}_{3}$. The solid phase obtained either at the end of the polymerisation process or via precipitation of low molecular weight species, undergoes several transformations between various oxide and oxohydroxide. The evolution of the metastable phases to less soluble ones was reviewed by M. Blesa and E. Matijevic in a recent paper [27].

Investigation of the process of iron(III) hydrolysis requires the employment of many techniques, due to its complexity. Many studies, including $\mathrm{pH}$ measurements, chemical analysis, turbidimetry, ultrafiltration $[28,29]$, electron microscopy $[4,11,15]$, spectrophotometry and light scattering $[13,16,30,31]$ were conducted to address this process. The polymer itself was isolated and characterised by means of these techniques. X-rays diffraction, IR, Mossbauer spectroscopy were also employed $[14,24,30]$ in an effort to characterise the intermediates involved.

\section{THE OXIDATION REACTION: A KINETIC STUDY}

The kinetics of iron(II) oxidation may control the formation and hydrolysis of iron(III) and modify the crystallisation processes of the resultant hydrolysis products of iron(III). This process in aqueous solution has been studied extensively. In fact the transformation of $\mathrm{Fe}^{2+}$ to $\mathrm{Fe}^{3+}$ occurs in natural waters, in many geochemical environments [33] and in the atmosphere [34]. 
The oxidising agent in these environments is commonly $\mathrm{O}_{2}$. Other studies discuss the oxidation by permanganate [35] and $\mathrm{H}_{2} \mathrm{O}_{2}$ [36]. In our work the kinetics of $\mathrm{Fe}^{2+}$ oxidation by $\mathrm{H}_{2} \mathrm{O}_{2}$

$$
\mathrm{H}_{2} \mathrm{O}_{2}+2 \mathrm{Fe}^{2+}+2 \mathrm{H}^{+} \rightarrow 2 \mathrm{Fe}^{3+}+2 \mathrm{H}_{2} \mathrm{O}
$$

was revisited as summarised below.

A stopped flow apparatus [37] equipped with a UV-Vis detector was utilised to monitor the fate of the oxidised product. As soon as the iron sulphate solution and $\mathrm{H}_{2} \mathrm{O}_{2}$ were mixed, the appearance of the $\mathrm{Fe}(\mathrm{OH})^{2+}$ species was monitored spectrophotometrically (the unhydrolysed $\mathrm{Fe}^{3+}$ was undetectable because the first step of hydrolysis was faster than the time resolution of the instrument). The reaction was found to be first order with respect to the concentration of total iron(II) and the oxidant, hydrogen peroxide, according to the equation:

$$
\mathrm{dFe}(\mathrm{III})] / \mathrm{dt}=\mathbf{k}[\mathrm{Fe}(\mathrm{II})]\left[\mathrm{H}_{2} \mathrm{O}_{2}\right]
$$

When the reactions were studies with an excess of $\mathrm{H}_{2} \mathrm{O}_{2}$ the reaction became pseudo first order:

$$
\mathrm{d}[\mathrm{Fe}(\mathrm{III})] / \mathrm{dt}=\mathbf{k}^{\prime}[\mathrm{Fe}(\mathrm{II})]
$$

In fact dependence of $\mathrm{k}^{\prime}$ on $\left[\mathrm{H}_{2} \mathrm{O}_{2}\right]$ was found linear over the range $1 \times 10^{-4}$ up to $0.5 \mathrm{M}$, in agreement with many past studies [38,39] (figure 3 ).

Other experiments showed that the rate constant is independent of $\mathrm{pH}$ below $\mathrm{pH}=4[40,41]$; while in the range of $\mathrm{pH} 4-7$ the dependence was linear (figure 4a). In fact the kinetics of the reaction strongly depends on [ $\left.\mathrm{OH}^{-}\right]$when oxidation and hydrolysis take place simoultaneously. Only at high $\mathrm{pH}$, when $\left[\mathrm{OH}^{-}\right]$is not negligible hydrolysis cooperate in accelerating the reaction of $\mathrm{Fe}^{2+}$.

In the range of ionic strength between 0 and 1 the rate constant was essentially independent of the ionic strength (figure $4 \mathrm{~b}$ ). As predicted by the 
theoretical treatment of Bronsted [42], a reaction that is not affected by the ionic strength of the solution must involve either neutral molecules or at least an ion and a neutral molecule. One can deduce that in our experiments at $\mathrm{pH}$ 4 the rate determining reagents were an ion, $\mathrm{Fe}^{2+}$ and a molecule, $\mathrm{H}_{2} \mathrm{O}_{2}$.

The oxidation of iron(II) was usually complete in between a few seconds to some tenths of seconds, depending on the experimental conditions.

The time range available with our stopped flow apparatus is $0.01 \mathrm{~s}$ up to $60 \mathrm{~m} \mathrm{~s}$. To broaden the time resolution we turned to the pulse radiolysis technique. The pulse radiolysis technique was utilised to generate $\mathrm{OH}$ radicals in $\mathrm{N}_{2} \mathrm{O}$ saturated (to convert $\mathrm{e}^{-}$aq to $\mathrm{OH}$ radicals) $\mathrm{FeSO}_{4}$ solutions at $\mathrm{pH} 4.5$. The reaction was followed either spectruphotometrically or by conductivity $[43,44]$. Figure 5 shows a 3 -dimensional presentation of the evolution of the spectra, up to $200 \mu \mathrm{s}$ following the initiating pulse. As can be seen in this figure the spectrum of $\mathrm{FeOH}^{2+}$ evolves with a halflife of $50 \mu \mathrm{s}$. This is attributed to reaction

$[6] \mathrm{Fe}^{2+}+\mathrm{OH} \rightarrow \mathrm{Fe}(\mathrm{OH})^{2+}$

The conductivity results, described below, agree with this interpretation.

Spectra at later times were recorded on the streak camera using progressively longer delay times between the pulse and the camera gating. Examples are shown in figures 6 and 7 for $10 \mathrm{~ms}$ and $60 \mathrm{~s}$ delay times respectively. At $10 \mathrm{~ms}$ the spectrum has shifted to peak at $350 \mathrm{~nm}$ (figure 6).

Since this shift is not accompanied by conductivity changes, we attribute it to a dimerisation-oxolation reaction of the type shown in reaction 1. As time progresses, in the sec time regime, the spectra continue to shift to the red (figure 7) with concomitant increase in the absorbance in the UV range. At 60 $\mathrm{s}$ after the pulse the spectra already exhibit the features of small colloidal particles with a shoulder at $390 \mathrm{~nm}$ and absorption threshold at $\lambda=420 \mathrm{~nm}$. The shift of absorption threshold to higher energies relative to that of large colloidal particles is attributed to the well known quantum size effect in small particles. 
Experiments conducted on similar solutions using the conductivity detection technique help identify the intermediate involved. Little conductivity change was observed in the ms regime. During this time $1<10$ $\mathrm{ms}$ ) only small increase in the solution conductance could be observed indicating only little hydrolysis of the product of reaction 6 .

From the small increase in conductance we estimate that approximately $20 \%$ of the initial product, $\mathrm{FeOH}^{2+}$, has hydrolysed according to reaction 7 within $10 \mathrm{~ms}$ after the pulse.

$$
\mathrm{FeOH}^{2+}+\mathrm{H}_{2} \mathrm{O} \rightarrow \mathrm{Fe}(\mathrm{OH})_{2}^{+}+\mathrm{H}^{+}
$$

As the time progresses the conductivity continuously increases with a * halflife of $40 \mathrm{sec}$ (figure 8).

It can be estimated from the plateau level at the end of this process that three protons were released per each $\mathrm{Fe}^{2+}$ that was oxidised. Among the common oxides or oxy-hydroxides, only hematite $\mathrm{Fe}_{2} \mathrm{O}_{3}$ will correspond to this stoichiometry.

We attribute this process to continuous polymerisation of the hydroxylated dimers followed by deprotonation of the hydroxo bridges as shown in reaction 2 . Since during this period of time the bulk of spectral features start to appear (albeit blue shifted), we conclude that the crystal lattice evolves during the polymerisation process.

\section{CONCLUSIONS}

The combination of kinetic, spectrophotometric and conductivity data collected here, with information available in the literature and some visual observations leads to the following mechanistic conclusions.

The oxidation of $\mathrm{Fe}^{2+}$ ions by $\mathrm{OH}$ radicals produces an adduct which is identical to the mono hydroxylated $\mathrm{Fe}^{3+}$ ion. At low $\mathrm{pH}$ 's this species will dehydroxylate to give the hexaaquo ion $\mathrm{Fe}^{3+}$. At $\mathrm{pH}^{3}$ s above the first hydrolysis constant it will initiate growth of oligomeric products. The 
production of these polymers is accompanied by deprotonation. It thus appears that the deprotonation is driven by the growth process rather than initiating it. The growth-deprotonation process leads to the formation of small particles of crystal structure similar to that of the bulk material. Eventually these particles flocculate on a time scale of few hours.

\section{REFERENCES}

[1] A.B. Lamb, J.Am.Chem.Soc. 1938, 60, 977.

[2] C.F.Baes, R.E.Mesmer, The hydrolysis of cations, Wiley Interscience New York 1976.

[3] R.M.Smith, A.Martell, Critical stability constants vol.4 Plenum Press New York 1976.

[4] P.Murphy, A.Posner, J.Quirk J.Colloid Int.Sci. 1976, $\underline{56}, 279$.

[5] E.Rabinovitch, W.H.Stockmayer J.Am.Chem.Soc. 1942, 44, 335 .

[6] V.Strahm, R.C.Patel, E.Matijevic J.Phys.Chem. 1979, $\underline{83}, 1689$.

[7] R.C.Turner, K.E.Miles Can.J.Chem. 1957, 35, 1002.

[8] R.J.Knight, R.N.Sylva J.Inorg.Nucl.Chem. 1975, 37, 779.

[9] C.M.Flynn Chem.Rev. 1984, 84, 31.

[10] J.H.A. van de Woude, P.L.De Bruyn Colloids Surf. 1983, 8, 55

[11] L.Matijevic, P.Scheiner J.Colloid Int. Sci. 1978, 63, 509.

[12] E.Matijevic Acc.Chem.Res. 1981, 14, 22.

[13] R.N.Sylva Rev.Pure Appl.Chem. 1972,, 22, 115.

[14] J.Dousma, P.De Bruyn J.Colloid Int.Sci. 1976, ㅌ6, 527.

[15] T.J.Spiro et al. J.Am.Chem.Soc. 1966, 88, 2721.

[16] G.W.Brady, C.Kurkjian et al. Biochemistry 1968, 7, 2185.

[17] P.J.Murphy et al. Aust.J.Soil Res. 1975, 13, 189.

[18] B.A.Sommer, T.G.Spiro et al. Bioinorg.Chem. 1973, 2 ,295.

[19] J.Dousma, P.L.De Bruyn J.Colloid Int.Sci 1978, 64, 154. 
[20] J.Dousma, P.L.De Bruyn J.Inorg.Nucl.Chem. 1979, 41, 1565.

[21] P.H.Hsu, S.E.Ragone J.Soil Sci. 1972, 23 , 17.

[22]P.J.Murphy et al. J.Colloid Inic.Sci. 1976, 56, 284.

[23] On the special topic of colloidal particles formed during the hydrolys of iron chloride, we quote the paper on their structural investigation by PCS SAXS by D.Tchoubar et al. in Langmuir 1991, 7, 398.

[24] R.D.Stramel, J.K.Thomas J.Colloid Int.Sci. 1986, 110,121.

[25] N.H.Penners, L.K. Koopal Colloids Surf. 1986, 19, 337.

[26] B.C.Faust,M.R.Hoffmann et al. J.Phys.Chem. 1989, 93, 6370.

[27] M.Blesa, E.Matijevic Adv.Colloid Int.Sci 1989, $29,173$.

[28] P.H.Hsu Clays Clay Miner. 1973, 21, 267.

[29] P.H.Hsu J.Soil Sci. 1972, 23, 409.

[30] J.Dousma, P.L.De Bruyn J.Colloid Int.Sci 1979, 72, 314.

[31] J.Dousma, P.L.De Bruyn ibidem 1976, 56, 527.

[32] S.Allerton, J.Renner et al. J.Am.Chem.Soc. 1966, 88, 3147.

[33] W.Davison, G.Seed Geochim.Cosmochim.Acta 1983, 47, 67.

[34] P.Behra, L.Sigg Nature 1990, 344, 419.

[35] J.R.Sutter, K.B.Park J.Phys.Chem. 1984, 88, 770.

[36] J.W.Moffett, R.G.Zika Envir.Sci.Technnl. 1987, 21, 804.

[37] A schematic diagram of the apparatus is shown in

P.A.Carosso, E.Pelizzetti J.Crystal Growth 1984, 68, 532.

[38] T.J.Hardwick Can.J.Chem. 1957, $\underline{35}, 428$.

[39] T.Rigg, W.Taylor, J.Weiss J.Chem.Phys. 1954, 22, 575.

[40] C.F.Wells, M.A.Salam J.Chem.Soc. 1968, A24,

[41] F.Millero,S.Sotolongo Geochim.Cosmochim.Acta 1989,53,1867.

[42] J.N.Bronsted Z.Physik.Chem. 1922, 102, 169

[43] A description of the technique, both the apparatus and the data analysis is found in M.S.Matheson, P.C.Lee, D.Meisel, E.Pelizzetti J.Phys.Chem. 1983, 87, 394.

[44] E.Borgarello, E.Pelizzetti, W.A.Mulac, D.Meisel

J.Chem.Soc. Faraday I 1985, 81, 143. 


\section{TABLE I}

Hydrolysis constants of $\mathrm{Fe}(\mathrm{II})$ and $\mathrm{Fe}(\mathrm{III}), \mathrm{T}=25^{\circ} \mathrm{C}, \mathrm{I}=0$

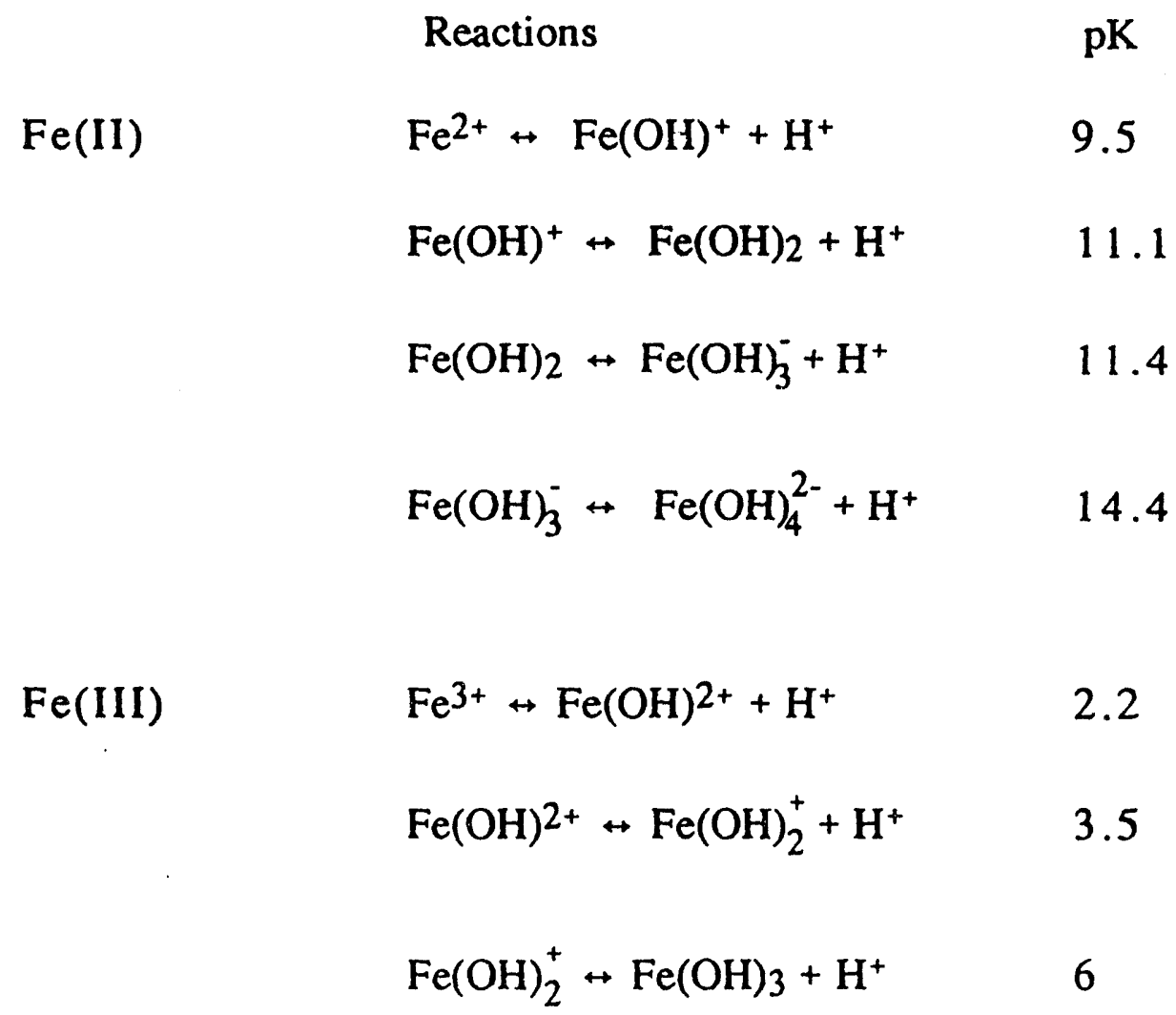




\section{TABLE II}

\section{Olation reaction matrix}

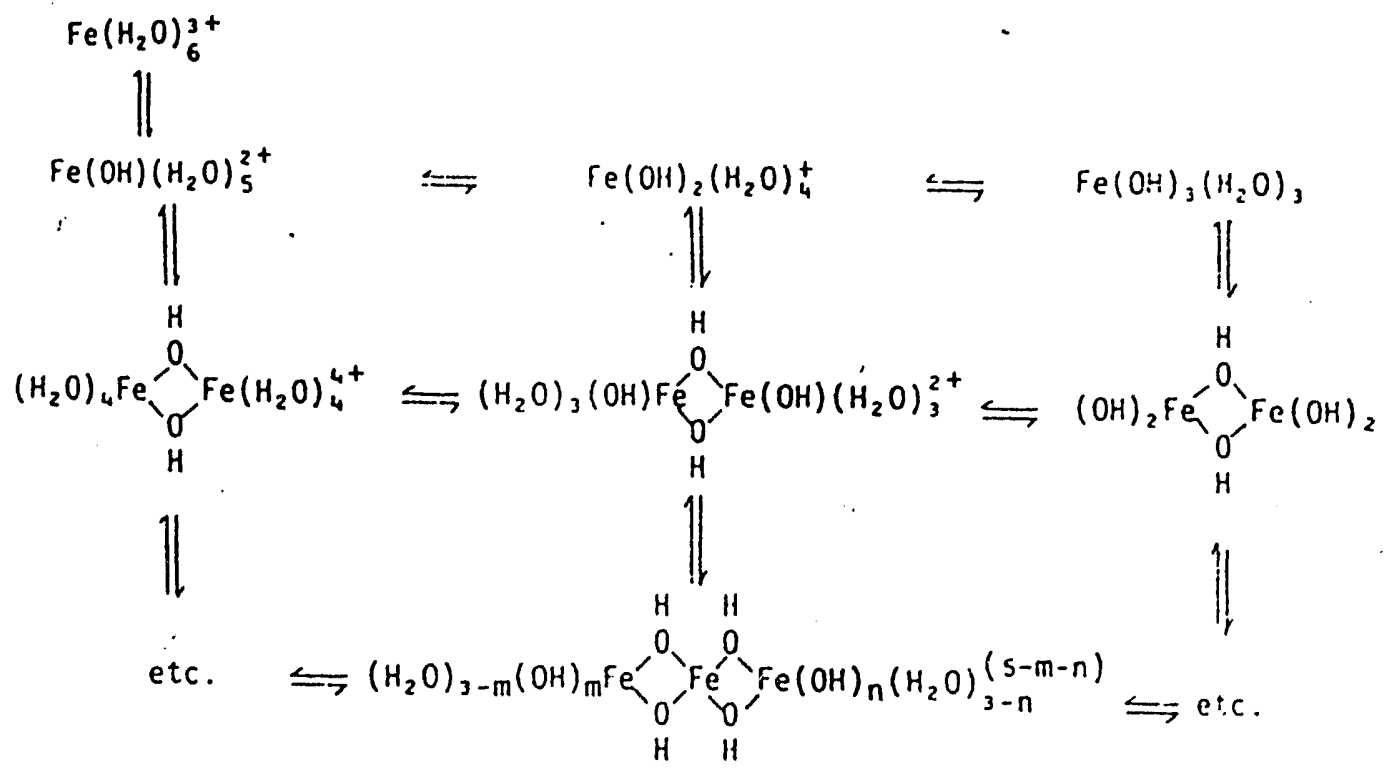


TABLE III

Aging processes in Fe(III) solutions after hydrolysis (numbers in parentheses give reaction times in seconds at $25^{\circ} \mathrm{C}$ )

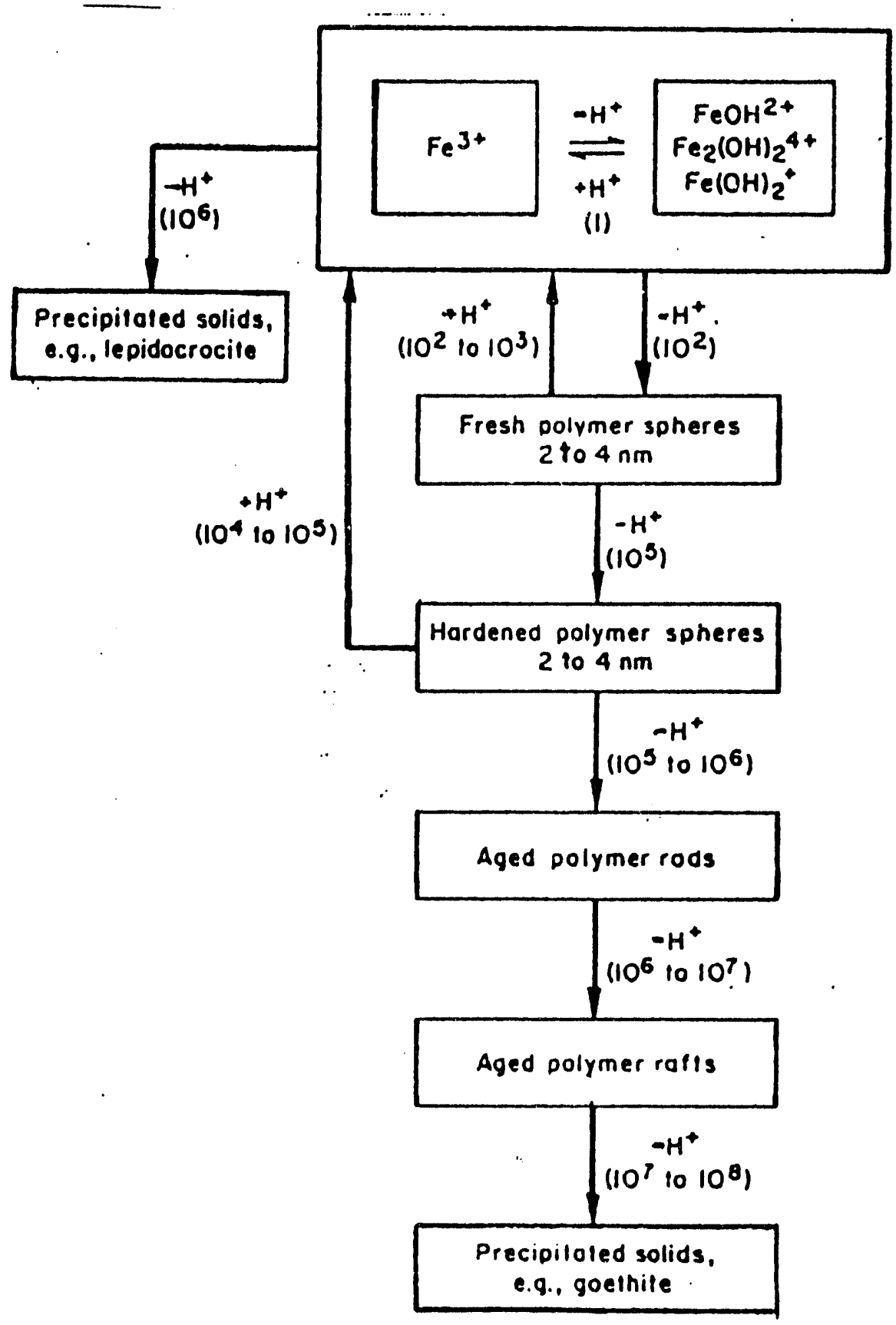




\section{FIGURE CAPTIONS}

Figure 1: UV-Vis spectra of a) $1 \times 10^{-3} \mathrm{M} \mathrm{FeSO}_{4}, \mathrm{pH}=4.5$; b) $1 \times 10^{-3} \mathrm{M}$ $\mathrm{Fe}\left(\mathrm{ClO}_{4}\right)_{3}$ in $\left.\mathrm{HClO}_{4} 0.1 \mathrm{M} ; \mathrm{c}\right) 1 \times 10^{-3} \mathrm{M} \mathrm{FeSO}_{4} \mathrm{pH}=1.9$ mixed with an equal volume of $\left.1 \times 10^{-2} \mathrm{M} \mathrm{H}_{2} \mathrm{O}_{2} ; \mathrm{d}\right) 1 \times 10^{-3} \mathrm{M} \mathrm{Fe}\left(\mathrm{ClO}_{4}\right)_{3}, \mathrm{pH}=1.5$ mixed with an equal volume of $\mathrm{NaOH} 0.05 \mathrm{M}$.

Figure 2: UV-Vis spectra of $\mathrm{Fe}\left(\mathrm{ClO}_{4}\right)_{3} 5 \times 10^{-5} \mathrm{M} \mathrm{pH}=1.5$ mixed with $\mathrm{NaOH}$ $1.2 \times 10^{-2} \mathrm{M}$ at various aging times ( 3 hours from a to $\mathrm{e}$ ).

Figure 3: Dependence of $\mathrm{K}_{\text {obs }}$ of iron oxidation on $\mathrm{H}_{2} \mathrm{O}_{2}$ concentration, $\left[\mathrm{FeSO}_{4}\right]=5 \times 10^{-4} \mathrm{M}, \mathrm{pH}=4$.

Figure 4: Dependence of $\mathrm{k}_{\mathrm{obs}}$ of iron oxidation on a) $\mathrm{pH}$ and b) ionic strength at $\mathrm{pH}=4,\left[\mathrm{FeSO}_{4}\right]=5 \times 10^{-4} \mathrm{M}_{2}\left[\mathrm{H}_{2} \mathrm{O}_{2}\right]=5 \times 10^{-3} \mathrm{M}$

Figure 5: Three dimensional (absorbance vs. wavelength vs. time) representation of streak camera results as observed for iron(II) oxidation, $\left[\mathrm{FeSO}_{4}\right]=1 \times 10^{-4} \mathrm{M}$. Time scale $200 \mu \mathrm{s}, 20 \mathrm{~ns}$ pulse.

Figure 6: Three dimensional (absorbance vs. wavelength vs. time) representation of streak camera results as observed for iron(II) oxidation, $\left[\mathrm{FeSO}_{4}\right]=1 \times 10^{-4} \mathrm{M}$. Time scale $200 \mu \mathrm{s}, 10 \mathrm{~ms}$ delay from the radiolytic pulse, 20ns pulse.

Figure 7: Three dimensional (absorbance vs. wavelength vs. time) representation of streak camera results as observed for iron(II) oxidation, 
$\left[\mathrm{FeSO}_{4}\right]=1 \times 10^{-4} \mathrm{M}$. Time scale $200 \mu \mathrm{s}, 60$ s delay from the radiolytic pulse, 20ns pulse.

Figure 8: Conductivity vs. time profile of iron(II) oxidation by $\mathrm{OH}$ radicals, $\left[\mathrm{FeSO}_{4}\right]=1 \times 10^{-4} \mathrm{M}$. Time scale $100 \mathrm{~s}, 4$ ns pulse. 
FIGURE 1

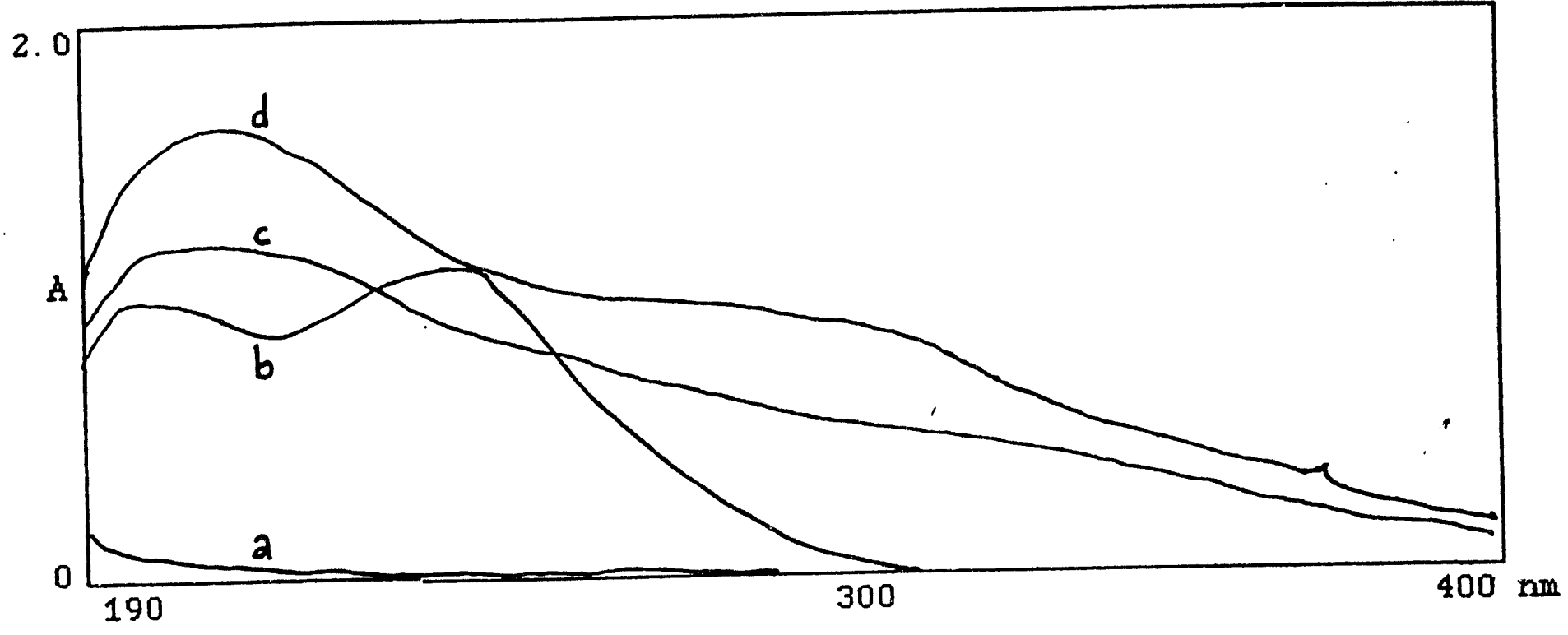

FIGURE 2

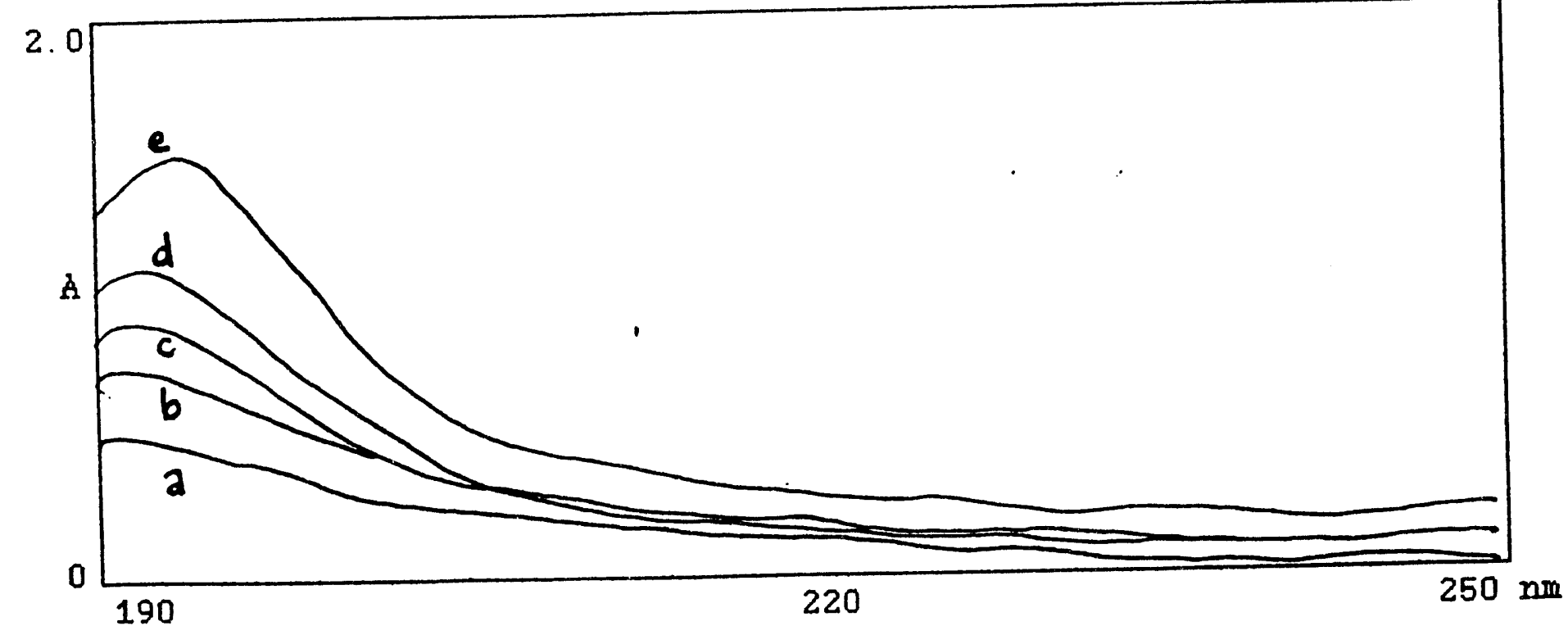




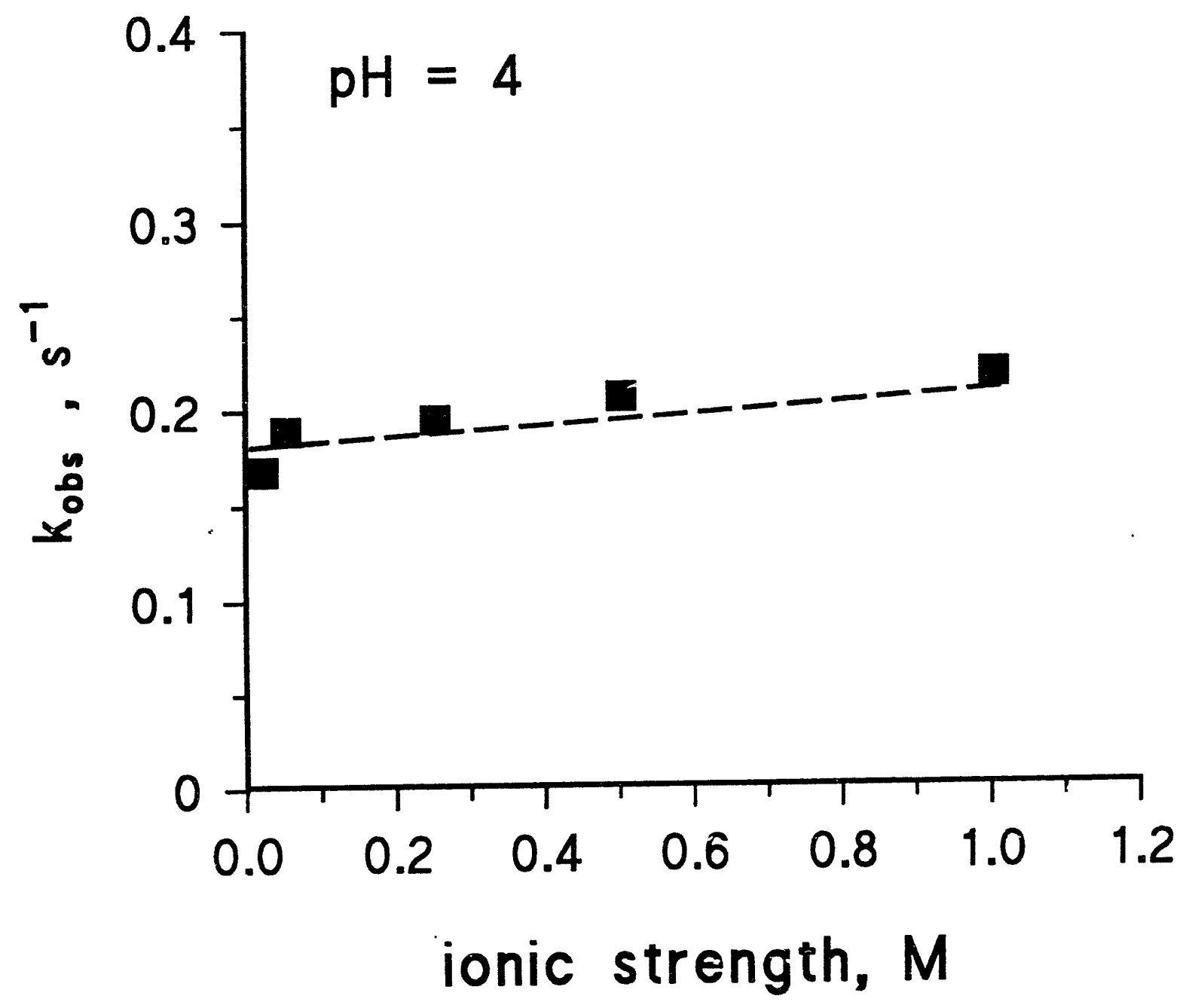




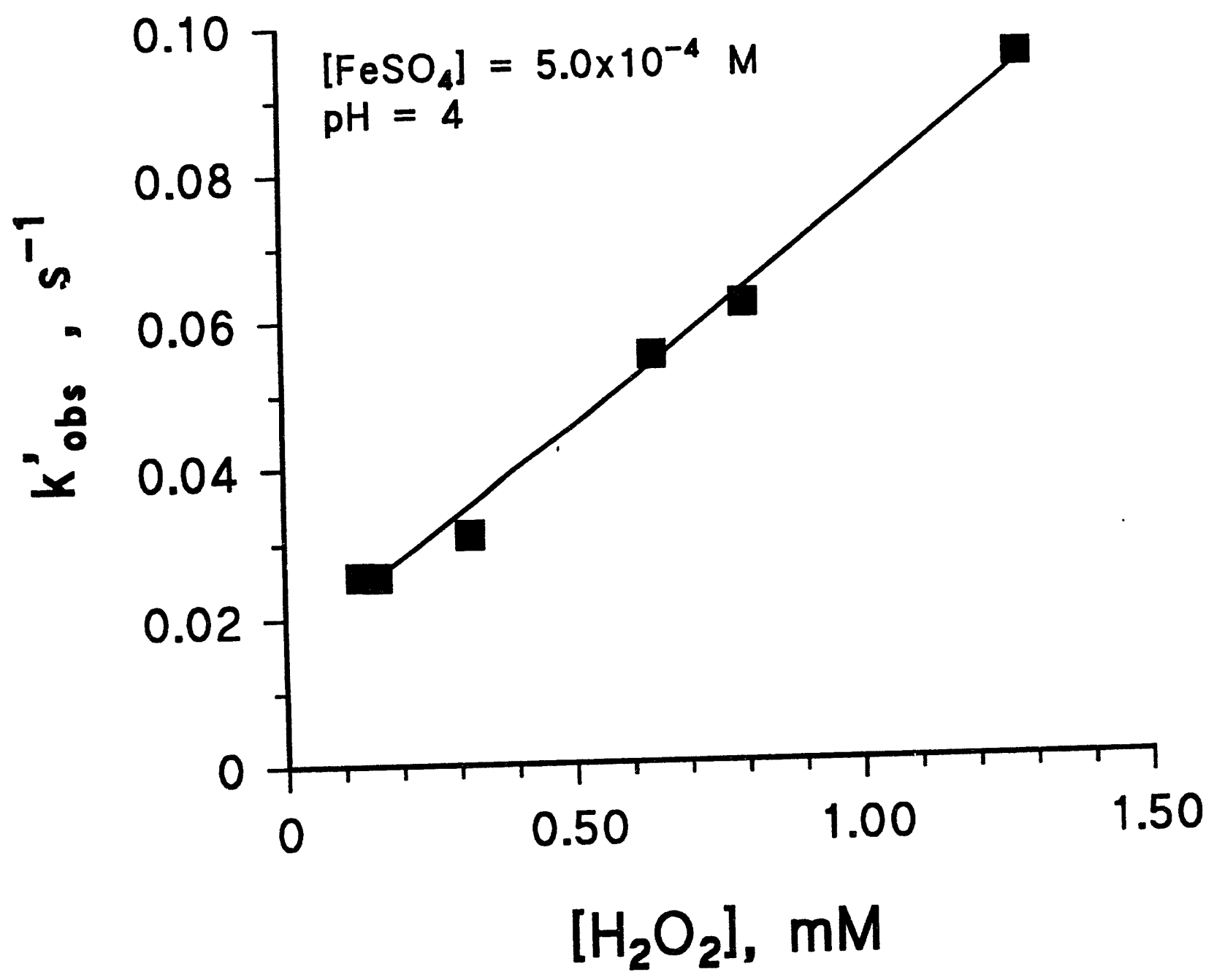




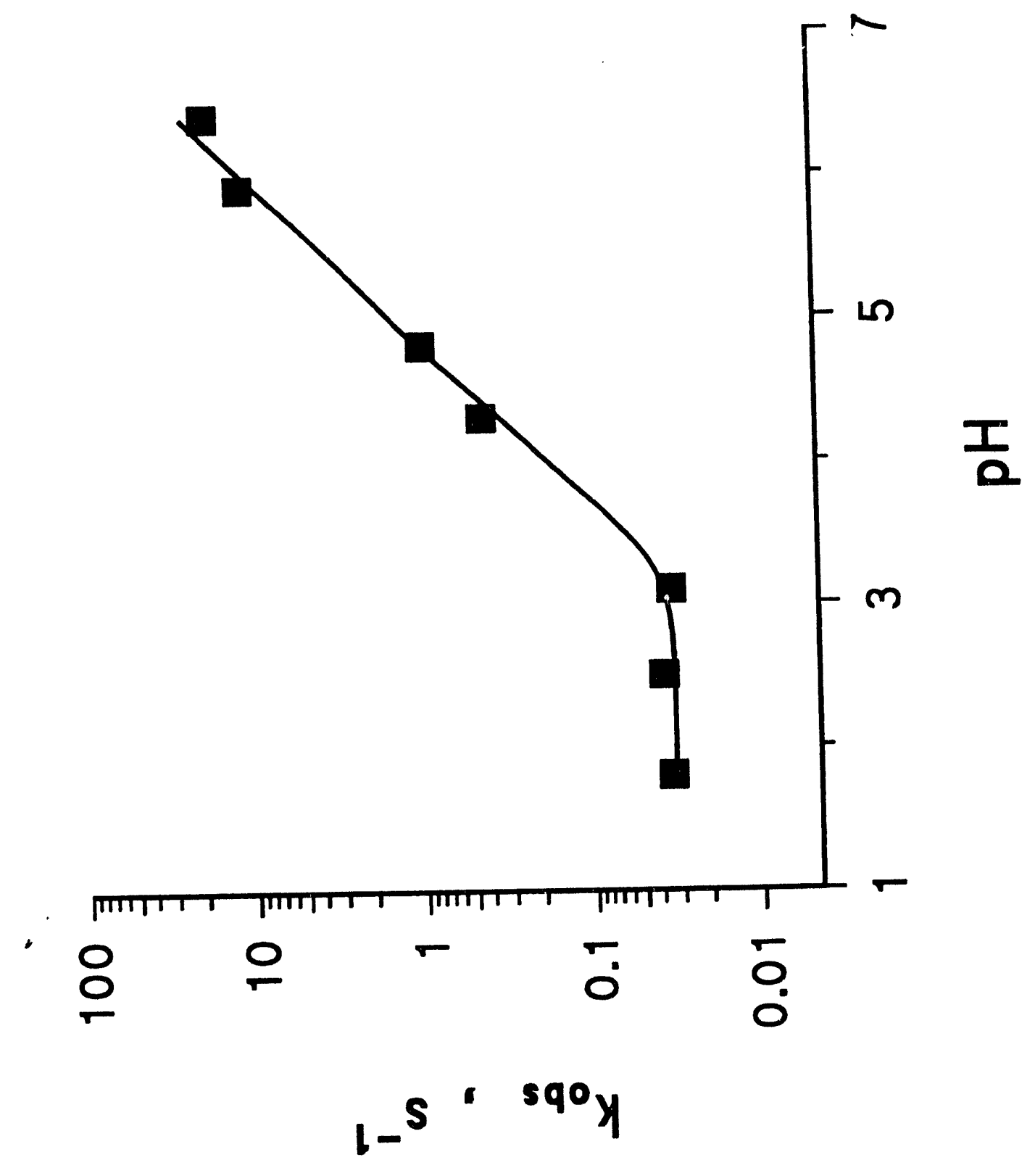




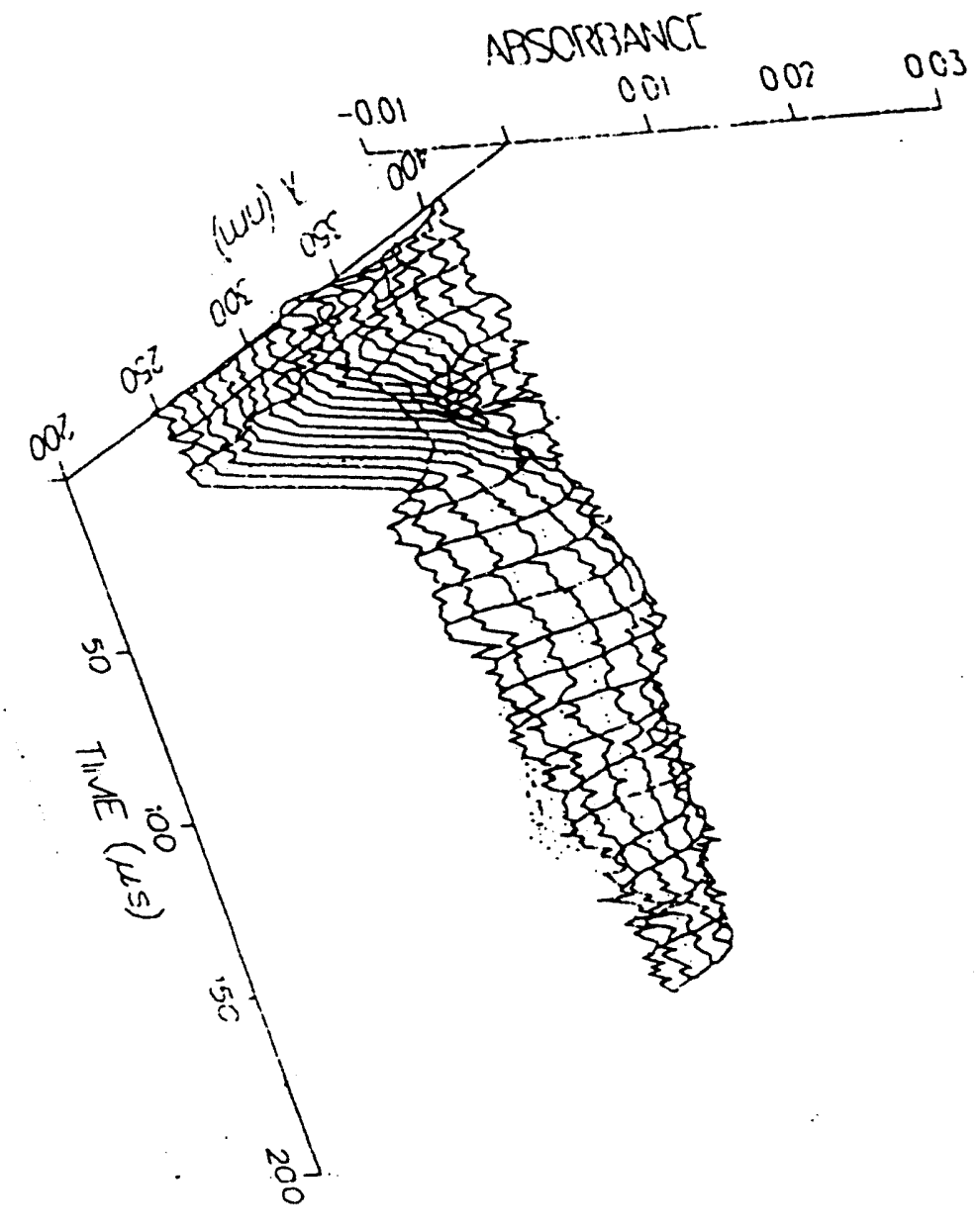

$\underset{\substack{\pi \\ n}}{\pi}$ 


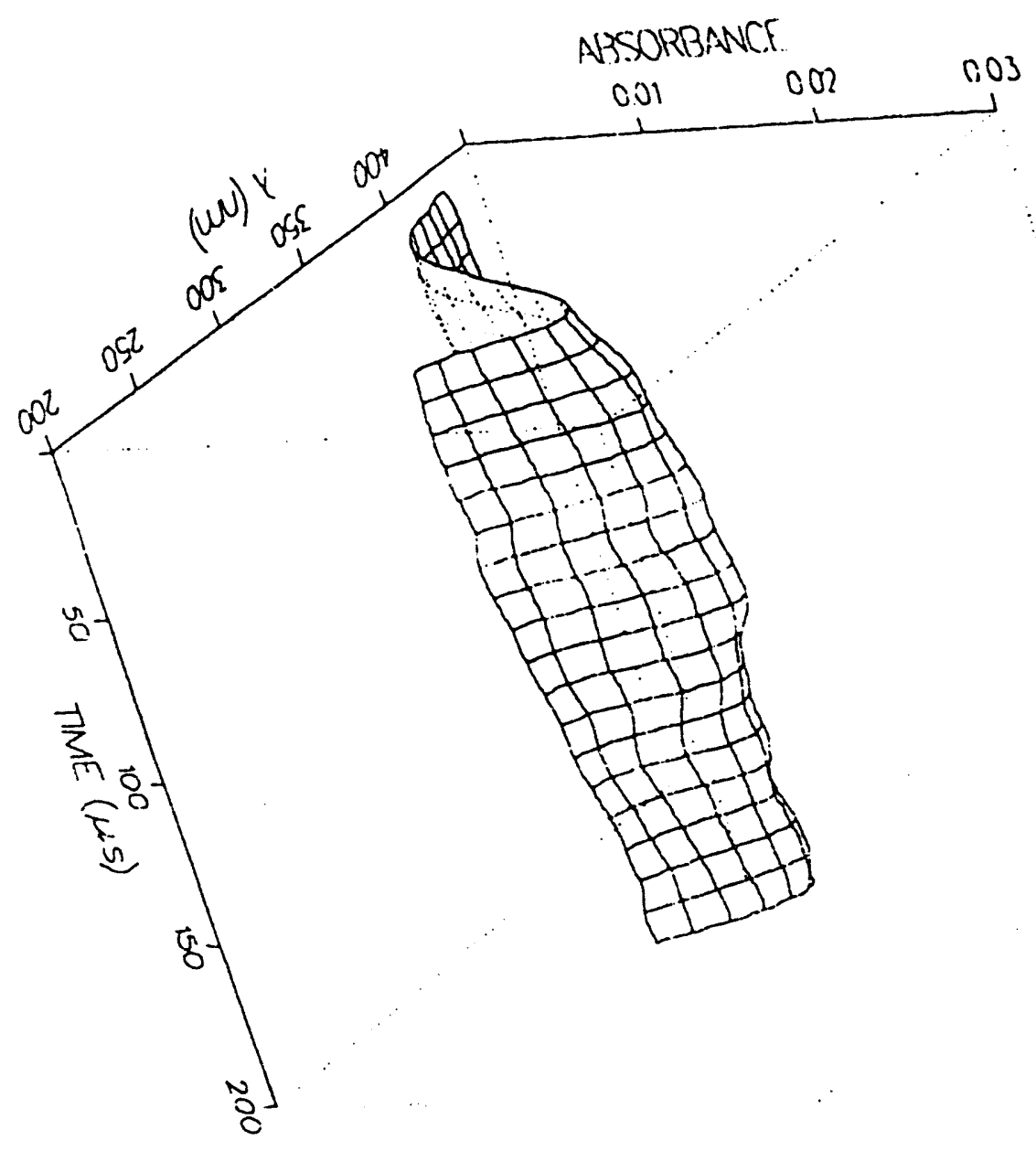

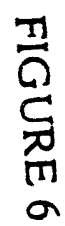

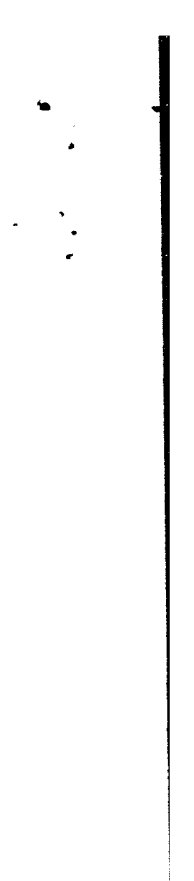



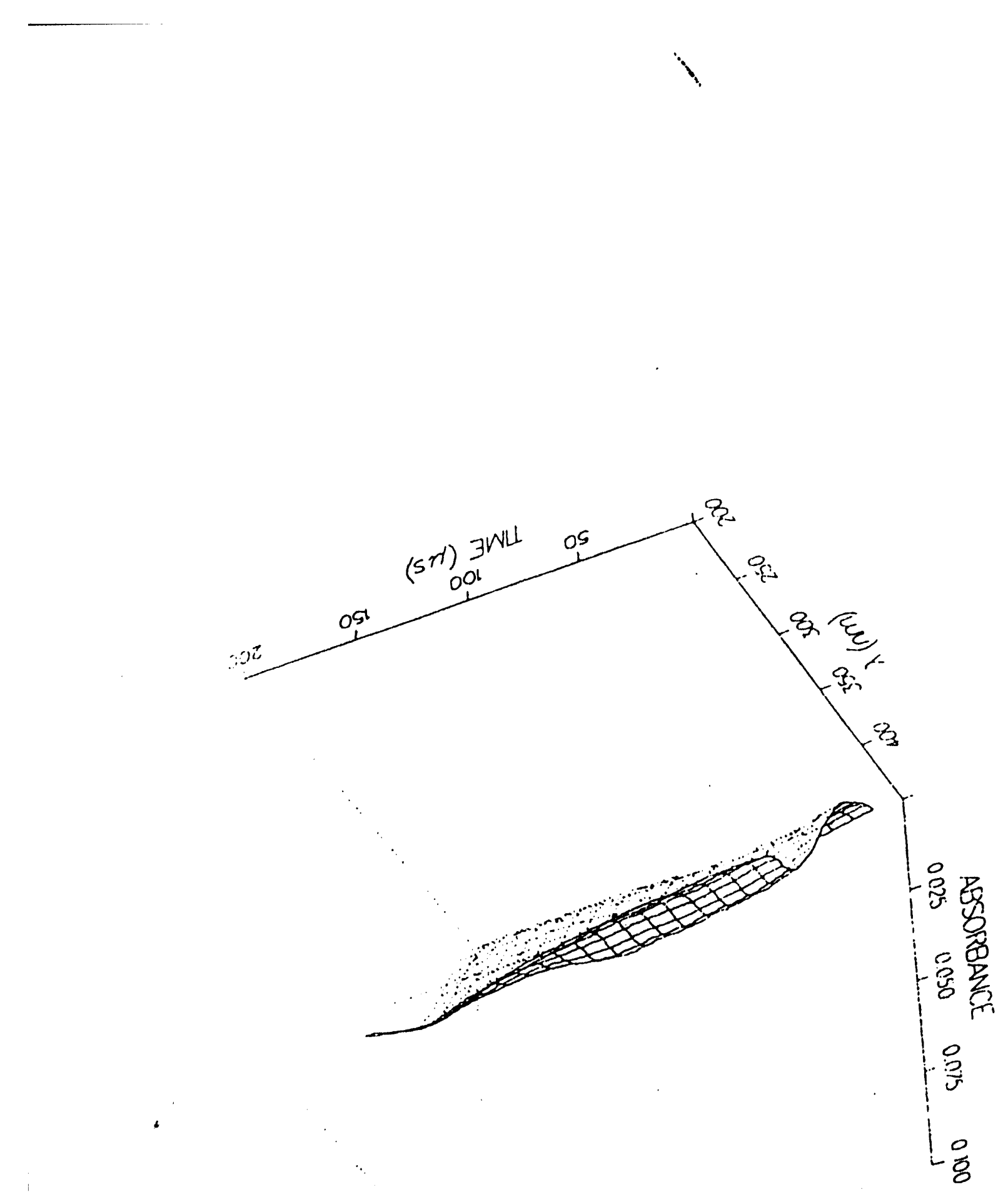

\section{L ayกDIA}


FIGURE 8

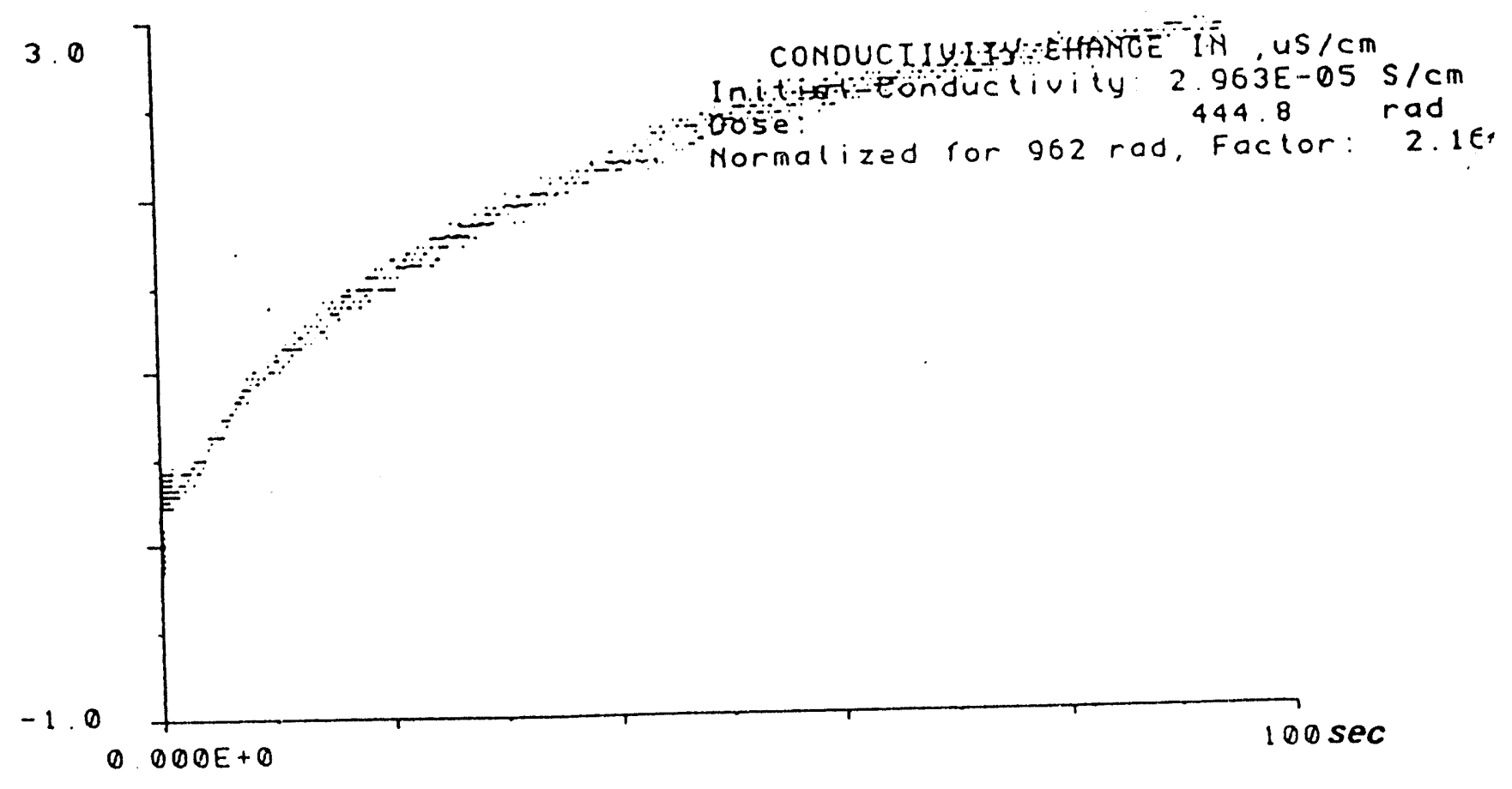



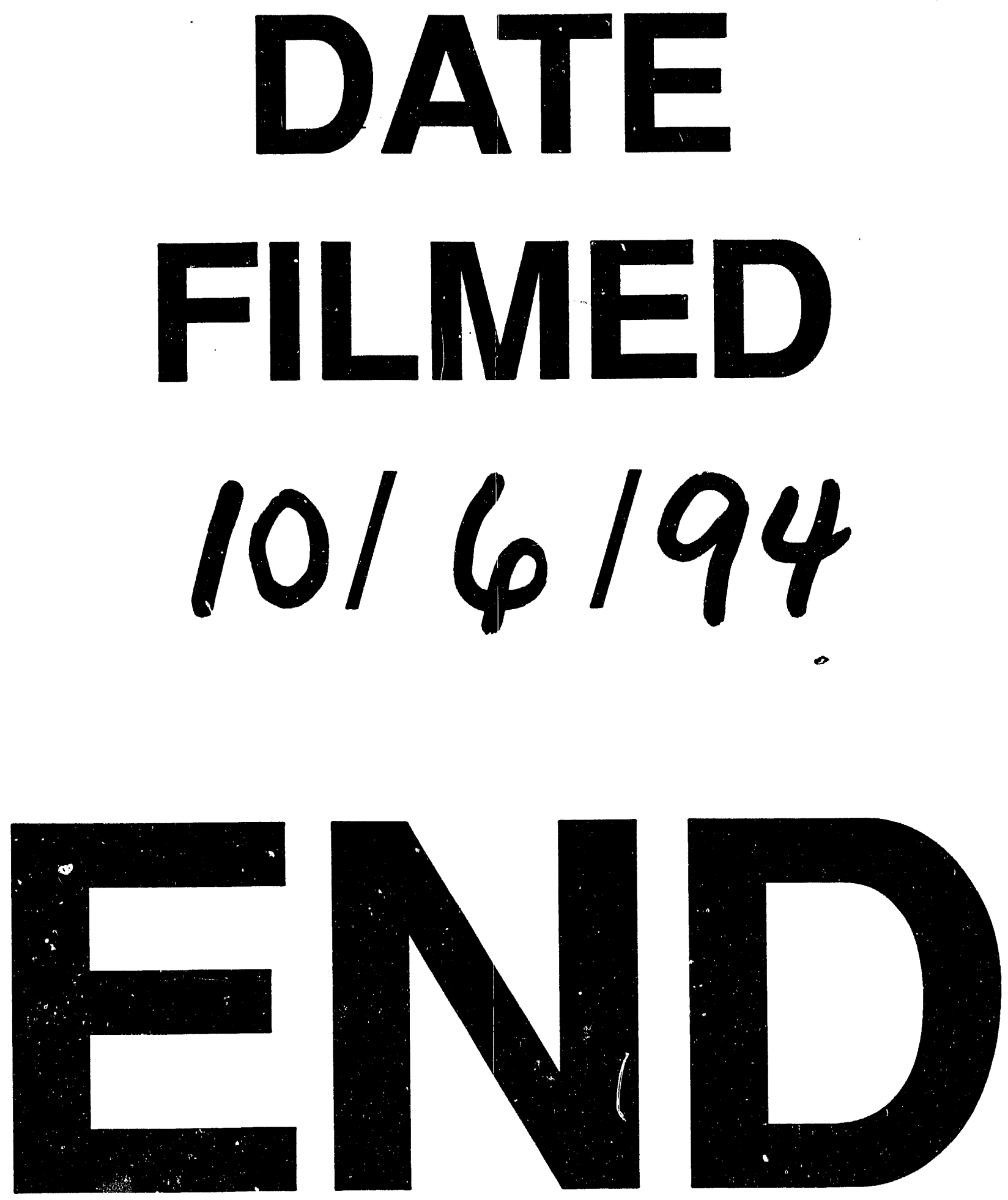
